\title{
Oxysterols regulate expression of the steroidogenic acute regulatory protein
}

\author{
S R King, A A Matassa ${ }^{1}$, E K White ${ }^{1}$, L P Walsh', Y Jo ${ }^{3}$, R M Rao ${ }^{3}$, D M Stocco ${ }^{3}$ \\ and M E Reyland ${ }^{2}$
}

Scott Department of Urology, Baylor College of Medicine, Houston, Texas 77030,USA

1'Department of Craniofacial Biology, School of Dentistry, University of Colorado Health Sciences Center, Denver, Colorado 80262, USA

${ }^{2}$ Department of Cell and Developmental Biology, School of Medicine, University of Colorado Health Sciences Center, Denver, Colorado 80262, USA

${ }^{3}$ Department of Cell Biology and Biochemistry, Texas Tech University Health Sciences Center, Lubbock, Texas 79430, USA

(Requests for offprints should be addressed to M E Reyland, Department of Craniofacial Biology, University of Colorado Health Sciences Center, 4200 East Ninth Avenue, Box C286, Denver, Colorado 80262; Email: mary.reyland@UCHSC.edu.)

\begin{abstract}
The steroidogenic acute regulatory (StAR) protein promotes intramitochondrial delivery of cholesterol to the cholesterol side-chain cleavage system, which catalyzes the first enzymatic step in all steroid synthesis. Intriguingly, substrate cholesterol derived from lipoprotein can upregulate StAR gene expression. Moreover, substrate oxysterols have been suggested to also play a role. To investigate whether oxysterols can regulate StAR expression, two steroidogenic cell lines, mouse Y1 adrenocortical and MA-10 Leydig tumor cells, were treated with various oxysterols and steroids, including 25 -hydroxycholesterol ( $25 \mathrm{OHC}), 22(\mathrm{R}) \mathrm{OHC}$ and $20 \alpha \mathrm{OHC}$. The majority of these compounds rapidly increased StAR protein levels within as little as $1 \mathrm{~h}$. The most potent oxysterols were $20 \mathrm{\alpha OHC}$ for $\mathrm{Y} 1$ and $25 \mathrm{OHC}$ for MA-10 cells. After $8 \mathrm{~h}$, StAR mRNA abundance also increased whereas there were no detected changes in promoter activity. Thus, in contrast to lipoprotein, oxysterols acutely increase StAR protein levels independently of mRNA abundance, and later increase mRNA levels independently of new gene transcription. Therefore, we propose that oxysterols modulate steroidogenesis at two levels. First, oxysterols may be important in post-transcriptional regulation of StAR activity and production of steroids for paracrine action. Secondly, through direct conversion to steroid, oxysterols may account in part for StAR-independent steroid production in the body.
\end{abstract}

Journal of Molecular Endocrinology (2004) 32, 507-517

\section{Introduction}

The steroidogenic acute regulatory (StAR) protein is a critical mitochondrial protein, which mediates the rate-limiting step in steroidogenesis (Stocco 2001). Upon trophic hormone stimulation, StAR is rapidly synthesized as a larger precursor in steroidogenic cells and, prior to or during mitochondrial import and processing, promotes the transfer of cholesterol from the outer to the inner mitochondrial membrane and the resident steroidogenic machinery (Krueger \& OrmeJohnson 1983, Clark et al. 1994, Bose et al. 1999, 2002). There, cholesterol is oxidized and converted to steroid by cytochrome $\mathrm{P} 450 \mathrm{scc}$, which is part of the cholesterol side-chain cleavage system. Thus, continual de novo synthesis of StAR ensures uninterrupted availability of cholesterol substrate to $\mathrm{P} 450 \mathrm{scc}$ for maximal steroid production. Mutations in StAR that compromise its activity give rise to congenital lipoid adrenal hyperplasia, with affected individuals showing a block in steroid synthesis and a pathological accumulation of cholesterol in their adrenal glands (Lin \& Sugwara 1995, Bose et al. 1996, Miller 1997). A similar phenotype is observed in mice in which the StAR gene is disrupted (Caron et al. 1997b).

The control of StAR expression is complex, involving both transcriptional and posttranscriptional mechanisms. Interestingly, elevations in cholesterol supplies derived from lipoprotein increase StAR mRNA and protein levels (Reyland 
et al. 2000), suggesting that substrate availability and steroid synthesis are linked in part through regulation of StAR activity. Other evidence indicates that StAR protein levels are also positively regulated by oxysterols. These compounds are generated from oxidation of cholesterol by specific hydroxylases that are present in many cell types in the body, including steroidogenic cells (Rennert et al. 1990, Russell 2000). Oxysterols regulate cholesterol and lipid homeostasis through, for instance, the transcription factors liver $\mathrm{X}$ receptor $\alpha$ and sterol regulatory element binding protein (SREBP) cleavageactivating protein (Edwards et al. 2002, Horton et al. 2002, Repa et al. 2002).

More hydrophilic than cholesterol, side-chain oxygenated sterols readily pass across lipophilic membranes and can translocate by diffusion into the mitochondria to $\mathrm{P} 450 \mathrm{scc}$ for direct conversion to steroid in the absence of StAR activity (Jefcoate et al. 1974, Meaney et al. 2002). However, oxysterols may also influence the synthesis of steroid from cholesterol, potentially through steroidogenic factor-1 (SF-1), an important transcription factor for StAR and steroidogenic enzyme gene expression (Lala et al. 1997, Mellon \& Bair 1998). Recently, it was shown that chronic treatment with oxysterols may also influence StAR protein levels in human luteinized granulosa cells in the absence of changes in mRNA (Christenson et al. 1998). The present studies were undertaken to investigate how oxysterols regulate the expression of StAR in steroidogenic cells. We show here that treatment of Y1 adrenocortical or MA-10 Leydig tumor cells with oxysterols results in a biphasic increase in StAR protein expression. Oxysterols cause an acute increase in StAR protein abundance that is independent of changes in StAR mRNA, but requires new protein synthesis. This acute increase is followed by a chronic increase in StAR protein that correlates with an elevation of StAR mRNA levels, but is independent of new StAR gene transcription.

\section{Materials and methods}

\section{Cell culture}

The stable Y1 subclone, BS1, was a generous gift of Dr Bernard P Schimmer (University of Toronto, ON, Canada) (Schimmer 1979). Cells were maintained in Ham's F10 medium supplemented with $100 \mathrm{U} / \mathrm{ml}$ penicillin, $100 \mathrm{mg} / \mathrm{ml}$ streptomycin, $2 \mathrm{mM}$ L-glutamine, $12 \cdot 5 \%$ heat-inactivated horse serum, and $2.5 \%$ heat-inactivated fetal calf serum. Subconfluent cells were serum-starved by pre-incubation for $20-24 \mathrm{~h}$ in minimal media (Ham's F10 media supplemented with 0.5\% BSA and 1\% Nutridoma SP from Roche, Indianapolis, IN, USA) prior to the addition of sterol. All cell culture reagents were purchased from Invitrogen (Grand Island, NY, USA). The mouse MA-10 Leydig tumor cell line was a gift of Dr Mario Ascoli (University of Iowa, Iowa City, IA, USA). Cells were maintained in Waymouth's MB 752/1 medium with $15 \%$ horse serum at $37^{\circ} \mathrm{C}$, in $5 \%$ $\mathrm{CO}_{2}$ as previously described (Ascoli et al. 1987). Cells were treated with dibutyryl cAMP (dbcAMP) (Sigma-Aldrich, St Louis, MO, USA), low-density lipoprotein (LDL) (Biomedical Technologies Inc., Stoughton, MA, USA) or sterols or steroids (Steraloids Inc., Newport, RI, USA) dissolved in ethanol $(\mathrm{EtOH})$. The final concentration of EtOH in media never exceeded $0 \cdot 1 \%$. Cycloheximide was purchased from Sigma-Aldrich.

\section{Northern blot analysis}

RNA was purified using RNA Stat-60 (Tel-Test Inc., Friendswood, TX, USA) for $\mathrm{Y} 1$ cells or TRIzol reagent (Invitrogen) for MA-10 cells according to the manufacturers' directions. Ten micrograms of total RNA were separated on a $1 \cdot 2 \%$ agarose gel containing $2 \cdot 2 \mathrm{M}$ formaldehyde, transferred to Nytran (Scheicher and Schuell, Keene, NH, USA), crosslinked with ultraviolet light using a Stratalinker (Stratagene, La Jolla, CA, USA), and hybridized to the indicated cDNA probe. cDNA probes were prepared by random priming in the presence of $\left[\alpha-{ }^{32} \mathrm{P}\right] \mathrm{dCTP}$ (Amersham Biosciences, Piscataway, NJ, USA) using mouse StAR cDNA and rat glyceraldehyde 3-phosphate dehydrogenase (GAPDH) cDNA (gift of Dr Kenneth B Marcu, State University of New York, Stony Brook, NY, USA). 18S rRNA probes were also labeled by random priming (Prime-It II; Stratagene) using $\left[\alpha-{ }^{32} \mathrm{P}\right] \mathrm{dCTP}$ (Easytides; Perkin Elmer, Boston, MA, USA). Hybridization was performed essentially as previously described (Walsh \& Stocco 2000). Levels of 18S rRNA, GAPDH and StAR mRNA were quantified using a Molecular Dynamics phosphorimager system (Amersham) for $\mathrm{Y} 1$ cells or by densitometry of 
autoradiograms using the Visage 2000 computerassisted image analysis system (BioImage, Ann Arbor, MI, USA) for MA-10 cells.

\section{Immunoblot analysis}

StAR protein expression was detected by immunoblot analysis as previously described using $50 \mu \mathrm{g}$ whole Y1 cell protein and 25 or $50 \mu \mathrm{g}$ mitochondrial protein from MA-10 cells (Wang et al. 1998, Reyland et al. 2000). Two different antisera generated against recombinant N62-truncated human StAR were generously provided by Drs Jerome F Strauss III (University of Pennsylvania Medical Center, Philadelphia, PA, USA) and Walter L Miller (University of California at San Francisco, CA, USA) and used to detect StAR protein in Y1 and MA-10 protein blots respectively (Pollack et al. 1997, Bose et al. 1999). Immunoreactive bands were visualized by chemiluminescence using ECL (Amersham) or Renaissance (Perkin Elmer) kits and were quantified by phosphorimaging or densitometry.

\section{Transient expression from the StAR promoter}

To investigate effects of oxysterols on StAR promoter activity, $\mathrm{Y} 1$ cells were co-transfected using the calcium phosphate method (Wigler et al. 1977) with a $966 \mathrm{bp}$ fragment of the mouse StAR promoter (p-966 StAR/luc) (gift of Dr Keith L Parker, University of Texas Southwestern Medical Center, Dallas, TX, USA) (Caron et al. 1997a) or a $1.3 \mathrm{~kb}$ fragment of the human StAR promoter (pGL1·3 kbStAR) (kindly supplied by Dr Strauss) (Sugawara et al. 1996) cloned into luciferase gene reporter constructs and pCMV $(\beta$-galactosidase $)$ as a control for transfection efficiency. The cells were incubated with the DNA/calcium phosphate mixture for $18 \mathrm{~h}$, washed with PBS, and further incubated in minimal media for $24 \mathrm{~h}$. Cells were then treated with sterols or LDL and harvested. Luciferase and $\beta$-galactosidase activities were assayed as previously described (Reyland et al. 1998).

\section{Results}

\section{Oxysterols increase StAR protein levels in steroidogenic cells}

To establish whether oxysterols affect the expression of StAR, we first investigated the effects of three different hydroxycholesterols (OHCs), $20 \alpha \mathrm{OHC}, 22(\mathrm{R}) \mathrm{OHC}$ and $25 \mathrm{OHC}$, on two different steroidogenic cell lines: Y1 adrenocortical cells and MA-10 Leydig tumor cells. All three oxysterols increased StAR protein levels in a concentration-dependent manner in Y1 cells (Fig. 1). The minimum effective concentration was $1 \mu \mathrm{g} / \mathrm{ml}$. In cells treated with $20 \alpha \mathrm{OHC}$ or 22( $\mathrm{R}) \mathrm{OHC}$, the maximal increase in StAR protein was observed at 5-10 $\mu \mathrm{g} / \mathrm{ml}$ hydroxysterol, while a further increase in StAR protein was seen with $15 \mu \mathrm{g} / \mathrm{ml} 25 \mathrm{OHC}$. Concentrations above $15 \mu \mathrm{g} / \mathrm{ml}$ were cytotoxic (data not shown). StAR protein levels were maximally increased over $24 \mathrm{~h}$ 6 -fold by $20 \alpha \mathrm{OHC}$ and 4 -fold by $22(\mathrm{R}) \mathrm{OHC}$ and 25 OHC. Similarly, when MA-10 cells were treated for $6 \mathrm{~h}$ with $20 \alpha \mathrm{OHC}, 22(\mathrm{R}) \mathrm{OHC}$ or $25 \mathrm{OHC}$, all three oxysterols caused a robust elevation of StAR protein levels, with $25 \mathrm{OHC}$ being the most potent (Fig. 2A and B). Although the fold increase seen in oxysterol-treated MA-10 cells was greater than that seen in Y1 cells, this appears to be due at least in part to a higher basal level of StAR protein expression in Y1 cells. Consistent with previous results with Leydig cells (Lukyanenko et al. 2001), MA-10 cells were resistant to cytotoxicity by oxysterols.

When Y1 cells were incubated with either $20 \alpha \mathrm{OHC}$ or $22(\mathrm{R}) \mathrm{OHC}$ for various time periods, we found that both oxysterols rapidly increased StAR protein within $1 \mathrm{~h}$ (Fig. 3). StAR levels continued to rise over $24 \mathrm{~h}$ with $20 \alpha \mathrm{OHC}$ treatment, whereas levels remained relatively constant after 6 h with 22(R)OHC. Some effect was also seen with $\mathrm{EtOH}$ alone, but it was always substantially less than with oxysterols.

\section{Various sterols and steroids increase StAR protein levels}

To determine if other sterols and steroid products could regulate StAR protein levels, cells were incubated with free cholesterol, 7-ketocholesterol (7 ketoC), 21-hydroxypregnenolone (21 OHpreg), progesterone, pregnenolone, and dehydroepiandosterone (DHEA) (Fig. 4A and B). We found that the oxysterol 7 ketoC also increased StAR protein, as did the steroids pregnenolone, progesterone and DHEA. In contrast, treatment with free cholesterol or 21 OHpreg had no effect on StAR protein expression. 

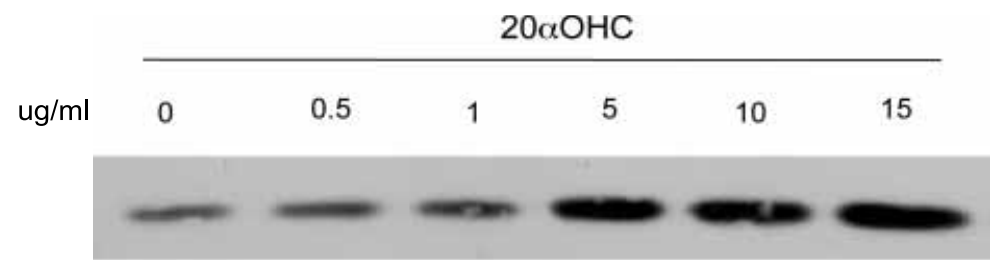

$29 \mathrm{kD}$

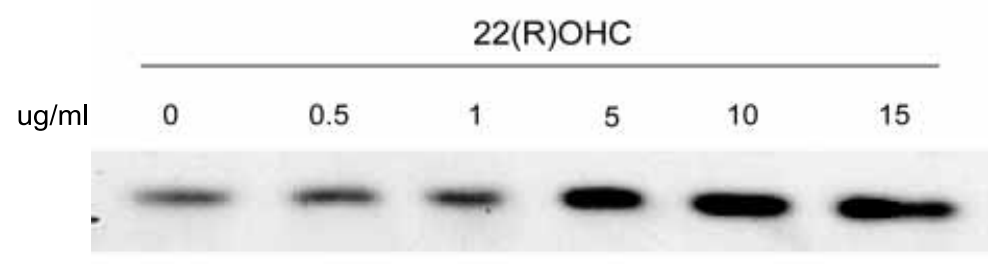

$29 \mathrm{kD}$

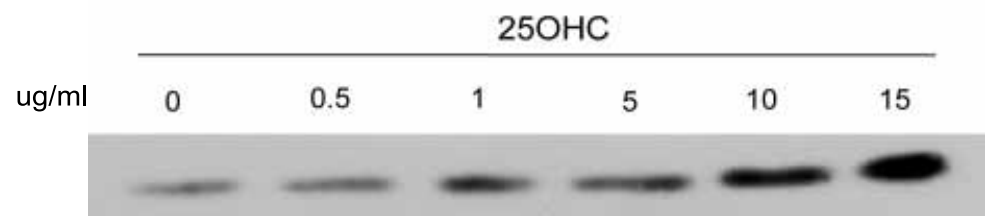

$29 \mathrm{kD}$

Figure 1 Oxysterols increase StAR protein levels in $Y 1$ adrenocortical cells in a concentration-dependent manner. $\mathrm{Y} 1$ cells were incubated with $\mathrm{EtOH}$ alone or varying concentrations of $20 \alpha-\mathrm{OHC}, 22(\mathrm{R}) \mathrm{OHC}$ or $25 \mathrm{OHC}$ for $24 \mathrm{~h}$. All three oxysterols increased StAR protein expression as determined by immunoblot analysis. This experiment was repeated twice with duplicate samples.

\section{Oxysterols increase StAR mRNA levels in steroidogenic cells}

To ask if the oxysterol-mediated increase in StAR protein abundance correlates with an increase in mRNA, Northern blot analysis was performed on $\mathrm{Y} 1$ cells treated for $24 \mathrm{~h}$ with various oxysterols. As seen in Fig. 5A and B, StAR mRNA increased in response to treatment with $20 \alpha \mathrm{OHC}$ and 22(R)OHG but not 25 OHG. The relative potency of the oxysterols was similar to that seen for StAR protein, with $20 \alpha \mathrm{OHC}$ eliciting the greatest increase (Fig. 5B).

To determine if StAR mRNA levels correlated with the increase in StAR protein, the time course of induction of StAR mRNA in 20aOHC-treated Y1 cells was determined (Fig. 5C). Interestingly, mRNA levels increased considerably after StAR protein levels began to rise. Thus, while StAR protein increased within $1 \mathrm{~h}$ of oxysterol addition (Fig. 3), StAR mRNA levels did not increase until after 8-12 h.

Similarly, MA-10 cells were treated with $20 \alpha \mathrm{OHC}, 22(\mathrm{R}) \mathrm{OHC}$ or $25 \mathrm{OHC}$ for 6 or $24 \mathrm{~h}$.
Northern blot analysis again revealed that shortterm treatment had no effect on StAR mRNA levels (Fig. 6A and $\mathrm{C}$ ). In contrast, after a $24 \mathrm{~h}$ incubation with oxysterol, StAR mRNA levels in MA-10 cells increased substantially over the control (Fig. 6B and C). This suggests that the acute increase in StAR protein abundance is not a result of increased transcription or mRNA stability. However, the persistent elevation in StAR protein could be due to the later rise in StAR mRNA levels.

To further explore whether the acute increase in StAR protein was due to increased stability or synthesis, Y1 cells were pretreated with the protein synthesis inhibitor cycloheximide prior to the addition of $20 \alpha \mathrm{OHC}$, and the accumulation of StAR protein over time was determined by immunoblot analysis (Fig. 7). As expected, treatment with cycloheximide significantly reduced the basal level of StAR protein in Y1 cells. Expression of StAR protein increased over time in cells treated with $20 \alpha \mathrm{OHC}$, but this increase was blocked by pretreatment with cycloheximide. Taken together, these data indicate that oxysterols acutely regulate StAR protein abundance at the level of translation. 
(a)

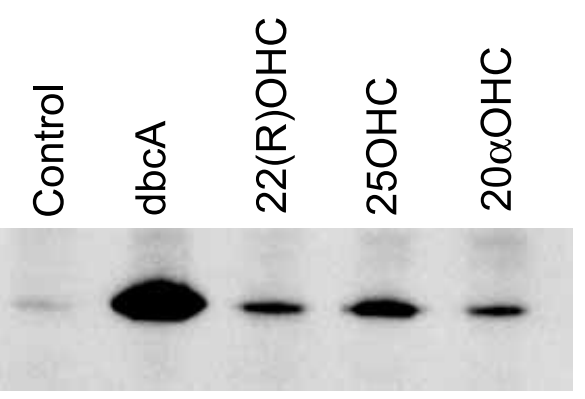

$29 \mathrm{kD}$

(b)

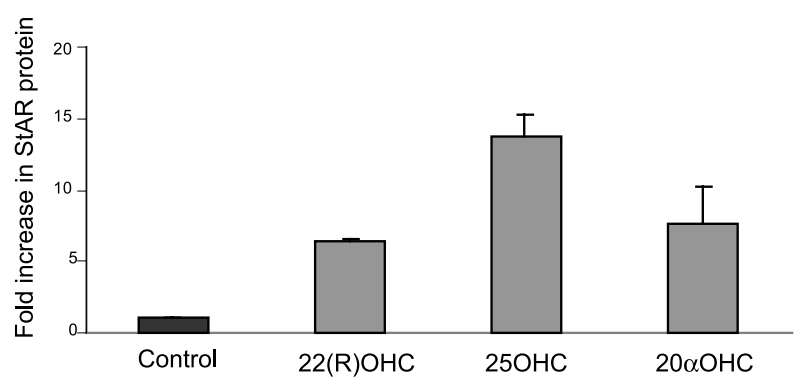

Figure 2 Oxysterols increase StAR protein levels in MA-10 Leydig cells. (A) MA-10 cells were treated for $6 \mathrm{~h}$ without (Control) or with $1 \mathrm{mM}$ dbcAMP (dbcA) or $15 \mu \mathrm{g} / \mathrm{ml}$ indicated oxysterol. Levels of StAR protein were significantly increased with $25 \mathrm{OHC}, 20 \alpha \mathrm{OHC}$ and 22(R)OHC as shown by immunoblot analysis. (B) Quantification of data from four similar experiments. The data are expressed as mean fold increase over control \pm S.D for four experiments.

\section{Oxysterol action is independent of StAR promoter activity}

To determine if the chronic increase in StAR mRNA abundance was due to changes in transcription, Y1 cells were transiently transfected with a mouse StAR gene promoter reporter plasmid, p-966 StAR/luc. Treatment of transfected cells with either $20 \alpha \mathrm{OHC}$ or 22(R)OHG for $24 \mathrm{~h}$ did not increase StAR promoter activity over levels in control or vehicle-treated cells (Fig. 8). Likewise, no increase in StAR promoter activity was observed when transfected cells were treated with oxysterols for $6-8 \mathrm{~h}$ (data not shown). In contrast, a known regulator of the StAR promoter, LDL, elicited a 2-fold increase in luciferase activity. Similar results were seen when Y1 cells were transfected with pGL1.3 kbStAR, which contains $1 \cdot 3 \mathrm{~kb}$ of the human StAR promoter upstream of luciferase (data not shown). No significant effect of $\mathrm{EtOH}$ on mRNA levels or promoter activity was observed. These findings indicate that the oxysterol-stimulated elevation in StAR mRNA is independent of any change in the rate of StAR gene transcription.

\section{Discussion}

Steroidogenic cells rapidly respond to trophic hormone stimulation with increased expression of

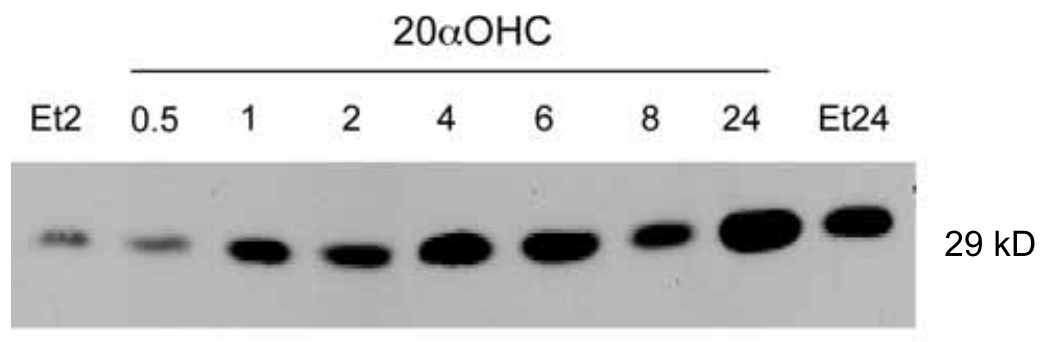

\section{2(R)OHC}

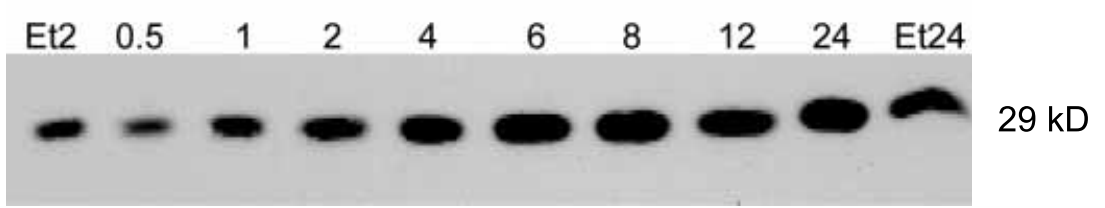

Figure 3 Oxysterols increase StAR protein levels in $\mathrm{Y} 1$ adrenocortical cells in a time-dependent manner. $\mathrm{Y} 1$ cells were incubated with $15 \mu \mathrm{g} / \mathrm{ml} 20 \alpha \mathrm{OHC}$ or 22(R)OHC or $\mathrm{EtOH}$ alone (Et) for different time periods (given in hours). Both oxysterols increased StAR protein levels as analyzed by immunoblot. This experiment was performed twice. 
(a)

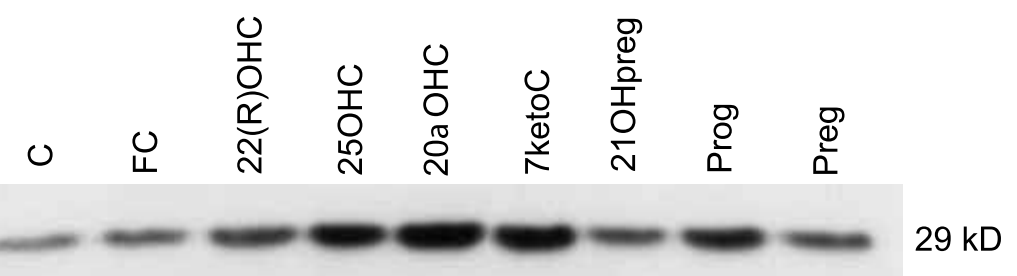

(b)

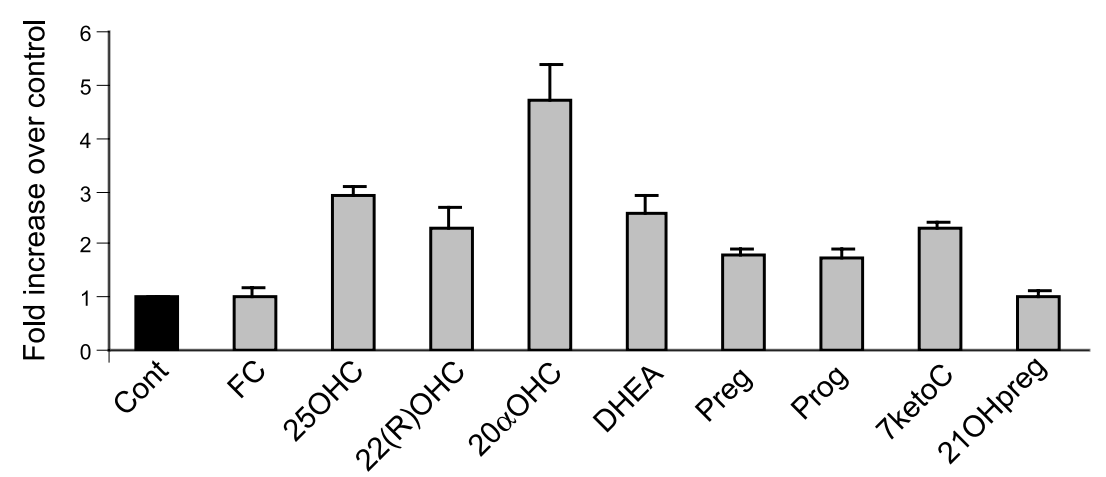

Figure 4 StAR protein levels are upregulated by both sterols and steroids. Y1 cells were incubated with $15 \mu \mathrm{g} / \mathrm{ml}$ free cholesterol (FC), 7 ketoC, 21 OHpreg, progesterone (Prog), pregnenolone (Preg), and DHEA or EtOH alone (lane marked C) for $24 \mathrm{~h}$. (A) Representative immunoblot of StAR protein levels. (B) Quantification of data from five similar experiments. The data are expressed as fold increase over control \pm S.D. (Cont). With the exception of $\mathrm{FC}$ and $21 \mathrm{OHpreg}$, all values are significantly different from the control $(P<0.05)$.

StAR and consequent steroid production. Given the essential role of StAR in steroid biosynthesis, much effort has been concentrated on understanding how this protein is regulated (Stocco et al. 2001). In addition to regulation at the transcriptional level, translational as well as post-translational control of StAR gene expression has been reported. The present data demonstrate that oxysterols, potent regulators of cholesterol and lipid metabolism (Björkhem 2002), may contribute to posttranscriptional regulation of StAR $\mathrm{mRNA}$ and protein.

Oxysterols exert a time-dependent biphasic effect on StAR expression in both Y1 and MA-10 cells. The early phase $(0-6 \mathrm{~h})$ appears to be independent of changes in StAR mRNA abundance, but requires new protein synthesis. This suggests that oxysterols may act to stabilize StAR protein or increase the rate of StAR mRNA translation. With prolonged stimulation (8-12 h), oxysterols also increase StAR mRNA levels, which may in turn promote the continued rise in the amount of StAR protein. These data suggest that in addition to functioning as a substrate for StAR-independent steroidogenesis via direct conversion to steroid, oxysterols may regulate the production of steroids indirectly through post-transcriptional regulation of StAR activity. This is in agreement with previous studies that have shown that production of StAR protein and steroid in the initial moments of trophic hormone stimulation may be independent of changes in mRNA abundance. Similar observations have been made for basal, potassiuminduced, and aspects of cAMP-stimulated StAR protein and steroid production (Clark et al. 1997, Clark \& Combs 1999, Artemenko et al. 2001). Since no precursor pool of StAR exists in the cell and the accumulation of StAR is cycloheximide-sensitive, these data suggest that StAR is translationally regulated. However, evidence for changes in the rate of StAR translation, especially in the early moments of hormonal stimulation, remains elusive 
(A) $\underline{\mathrm{ETOH}} 20 \alpha \mathrm{OHC} \quad 22(\mathrm{R}) \mathrm{OHC} \quad 25 \mathrm{OHC}$

StAR

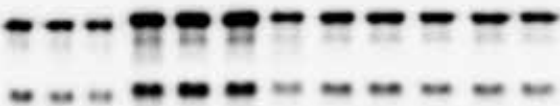

$3.4 \mathrm{~kb}$

$1.6 \mathrm{~kb}$

GAPDH

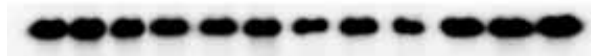

(B)

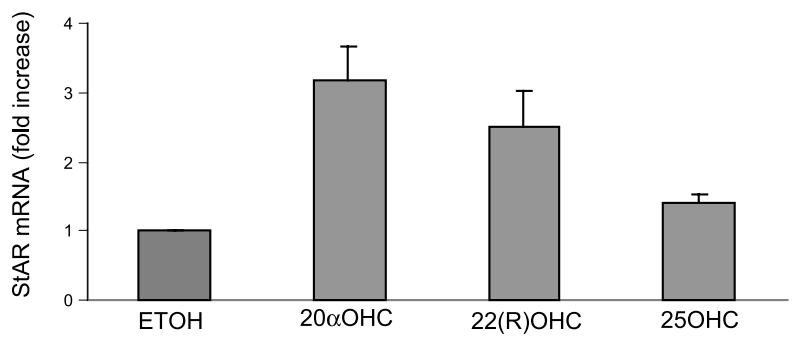

(C)

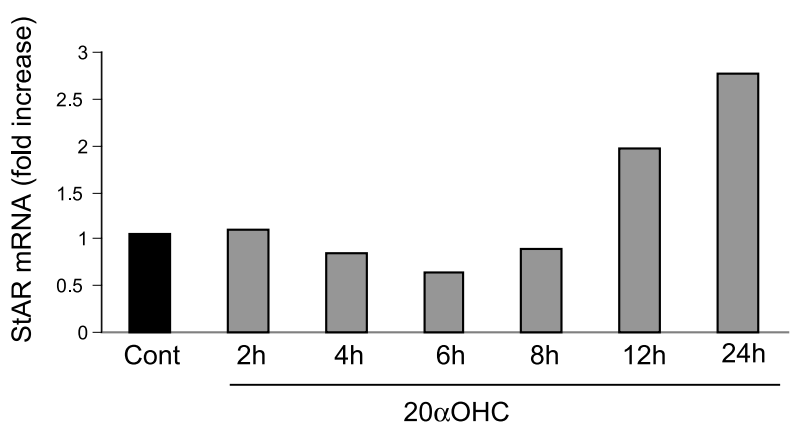

Figure 5 Oxysterols increase StAR mRNA levels in $Y 1$ cells in a time-dependent manner. $Y 1$ cells were incubated with $15 \mu \mathrm{g} / \mathrm{ml} 20 \alpha \mathrm{OHC}, 22(\mathrm{R}) \mathrm{OHC}$ or 25 $\mathrm{OHC}$ or $\mathrm{EtOH}$ alone (ETOH) for $24 \mathrm{~h}$. StAR mRNA expression was then assessed by Northern blot (A, top panel). The blot was later stripped and re-probed for GAPDH mRNA to control for loading differences (bottom panel). (B) Results of Northern blot analyses were quantified and normalized to GAPDH expression. The data from four experiments were then averaged and are expressed as fold increase over control \pm S.E.M. By Students' $t$-test, StAR mRNA levels were significantly increased by $20 \alpha \mathrm{OHC}$ and 22(R)OHC $(P<0.05)$ unlike with $25 \mathrm{OHC}(P=0.08)$. (C) Time course of StAR mRNA expression in cells treated with $20 \alpha \mathrm{OHC}$ compared with EtOH control (Cont) at $24 \mathrm{~h}$. StAR mRNA expression was normalized to GAPDH levels. This experiment was repeated three times. Values represent the average of duplicate measurements in a single experiment.

(Artemenko et al. 2001, Clark et al. 2001). Alternatively, oxysterols may simply reduce the degradation rate of non-functional mature StAR protein.
(A)

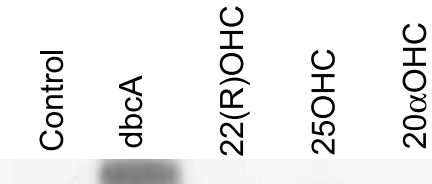

StAR

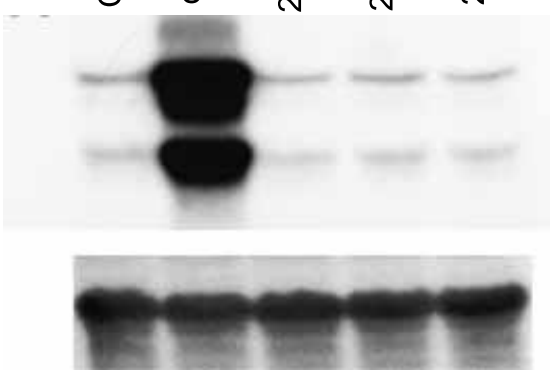

(B)

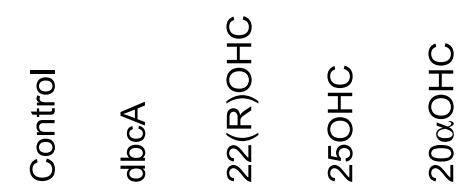

StAR

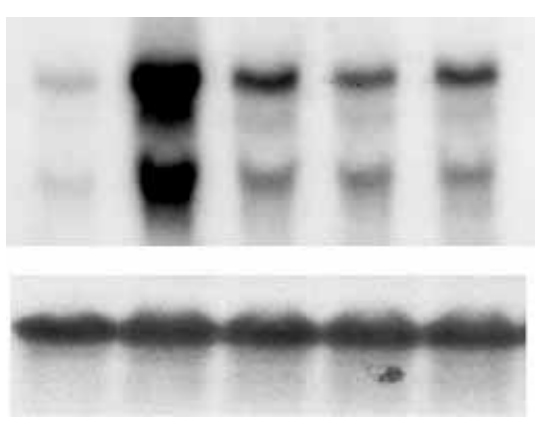

$3.4 \mathrm{~kb}$

$1.6 \mathrm{~kb}$

(C)

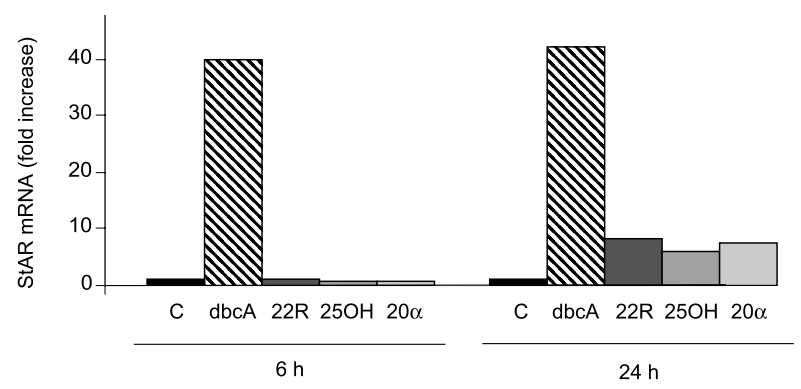

Figure 6 Oxysterols increase StAR mRNA levels in MA-10 cells. MA-10 cells were treated without (Control) or with $1 \mathrm{mM}$ dbcAMP (dbcA) or $15 \mu \mathrm{g} / \mathrm{ml} 20 \alpha \mathrm{OHC}$, $22(\mathrm{R}) \mathrm{OHC}$ or $25 \mathrm{OHC}$ for $6 \mathrm{~h}(\mathrm{~A})$ or $24 \mathrm{~h}(\mathrm{~B})$.

Oxysterols, especially $25 \mathrm{OHC}$, increased levels of StAR mRNA at both time points, although far less than dbcAMP, as verified by comparison with 18S rRNA levels as a loading control (below top panels). These results are quantified in (C).

The most potent sterol compounds were the side-chain oxygenated sterols 20aOHC and 25 $\mathrm{OHC}$, which elevated levels of StAR protein 4- to 


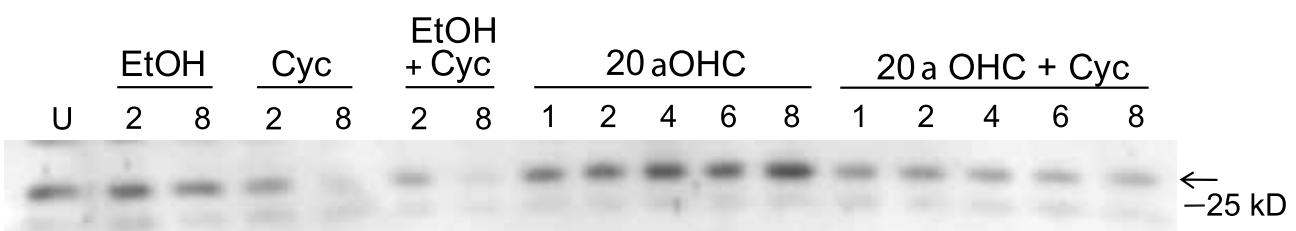

Figure 7 Acute regulation of StAR protein by oxysterol is inhibited by cycloheximide (cyc). Y1 cells were treated with $20 \alpha \mathrm{OH}(15 \mu \mathrm{g} / \mathrm{ml})$ for $1-8 \mathrm{~h}$, or pretreated with $50 \mu \mathrm{g} / \mathrm{ml}$ cycloheximide for $30 \mathrm{~min}$ prior to the addition of $20 \alpha \mathrm{OH}$. As a control, cells were treated with EtOH alone or cycloheximide alone for 2 or $8 \mathrm{~h}$. StAR protein expression (see arrow) was analyzed by immunoblot as described. This experiment was performed twice with duplicate samples.

6-fold within $6 \mathrm{~h}$. Interestingly, 20aOHC was most effective in increasing StAR protein in Y1 cells, while $25 \mathrm{OHC}$ was more effective in MA-10 cells. Sterol oxidized in the 7 position also significantly stimulated StAR protein levels, whereas free cholesterol had no effect, possibly due to a low rate of uptake by the cells (Meaney et al. 2002). Steroids such as DHEA and pregnenolone also increased StAR protein levels, although generally not as strongly as oxysterols. This is consistent with previous data obtained with progesterone, where interestingly, StAR mRNA levels were found to be increased (Schwarzenbach et al. 2003). However, it is unclear whether progesterone, unlike oxysterols, increases StAR gene transcription since another report showed no effect of progesterone on promoter activity (Christenson et al. 1998). Interestingly, oxidation of carbon-21 in the pregnenolone side-chain eliminated its ability to upregulate StAR

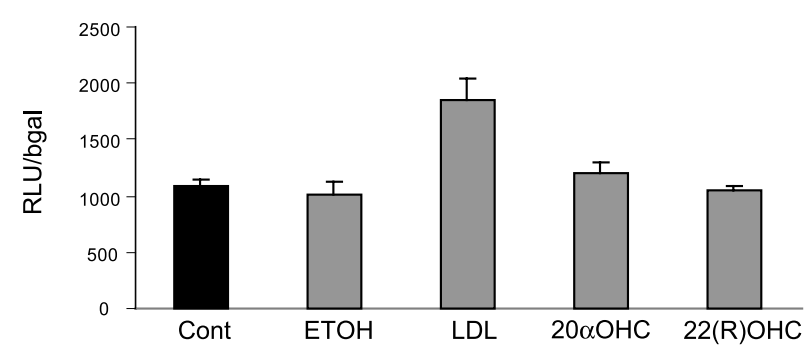

Figure 8 Oxysterols do not increase StAR transcription. $Y 1$ cells transiently transfected with p-966 StAR/luc and pCMV $\beta$-galactosidase were incubated without (Cont) or with $\mathrm{EtOH}(\mathrm{ETOH}), 15 \mu \mathrm{g} / \mathrm{ml} 20 \alpha \mathrm{OHC}$ or $22(\mathrm{R}) \mathrm{OHC}$ or $50 \mu \mathrm{g} / \mathrm{ml}$ LDL for 22-24 h. Luciferase and $\beta$-galactosidase activities were assayed and values are expressed as relative light units (RLUs) of luciferase normalized to $\beta$-galactosidase activity. Values are the average of quadruplicate samples in the same experiment \pm S.D., and are representative of four similar experiments, two for LDL. protein. In toto, these results point to a lack of feedback inhibition of steroidogenesis in vitro. In support of this, chronic trophic stimulation of steroidogenic cells causes excessive StAR mRNA and protein levels to subside only partially from their peak (Clark et al. 1995). Thus, the apparent decline in steroid output observed with chronic hormone stimulation may primarily result from increased steroid metabolism and the suppression of enzymes downstream in the steroidogenic pathway, with a resulting increased synthesis of alternative steroids (Yee \& Hutson 1985, Rommerts et al. 2001, Chen et al. 2002, Javitt 2002).

While oxysterol treatment did not cause an acute increase in StAR mRNA, the later increase in mRNA levels was surprising, differing from previous observations in granulosa cells incubated in delipidated media, which might still contain serum oxysterol (Christenson et al. 1998). Interestingly, although transcriptional regulation by oxysterols has been debated, we found no consistent effect on transcription from either the mouse or human StAR promoter at any of the time points examined (Lala et al. 1997, Christenson et al. 1998, Mellon \& Bair 1998). It may be that the relevant binding element for oxysterol action was excluded in the promoter fragments utilized, or that the later increase in StAR mRNA levels simply reflects a lowered degradation rate, as previously observed with actinomycin D (Clark et al. 1997).

In contrast to oxysterols, LDL increases StAR expression through upregulation of StAR promoter activity using an SF-1 site at - 135 in the murine StAR promoter, suggesting involvement of SF-1 (Reyland et al. 2000). The effect of LDL would probably not be enhanced by oxysterols since neither the P450 scc inhibitor aminoglutethimide, nor ketoconazole, which inhibits synthesis and 
conversion of cholesterol to hydroxycholesterol or steroid, affects LDL-induced increases in StAR mRNA levels (Reyland et al. 2000). Taken together, these data suggest that increased substrate cholesterol availability may promote StAR protein synthesis. However, oxysterols and lipoprotein act via distinct mechanisms, with LDL acting primarily at the level of transcription while oxysterols appear to act post-transcriptionally.

The importance of oxysterol regulation of StAR is unclear, given how minor its effect is compared with dbcAMP. Oxysterol action may be essential for increasing steroid synthesis in the first minute of trophic hormone stimulation through translational regulation or stabilization of the active form of StAR (Clark \& Combs 1999, Artemenko et al. 2001, Clark et al. 2001). The level of steroid consequently elicited may be appropriately small in order to be non-depleting, since cholesterol supply pathways are not activated by oxysterol (Javitt 2002). This would be advantageous since low steroid hormone concentrations may permit more targeted, local actions by steroid hormones as opposed to the systemic effects mediated by high endocrine levels generated in response to pituitary signaling. The higher sensitivity of MA-10 cells to 25 OHC may reflect just such a physiological situation in the testis. There, comparable levels of 25 OHC produced by testicular macrophages can induce differentiation of primary rat progenitor and immature Leydig cells and long-lasting increases in 'basal' steroidogenesis in adult Leydig cells; 25 OHC further elicits the generation of up to 3-fold higher concentrations of testosterone than of the oxysterol itself, indicating that the induced production of steroid is not simply a result of direct conversion of $25 \mathrm{OHC}$ to testosterone (Yee \& Hutson 1985, Lukyanenko et al. 2001, Chen et al. 2002). Thus, the loss of oxysterol production in testes depleted of macrophages may account for the observed reduction in steroidogenic enzyme and testosterone levels (Bergh et al. 1993, Cohen et al. 1997).

The present data are consistent with a general role for oxysterols in cholesterol metabolism (Javitt 2002). Oxysterols upregulate pro-lipogenic SREBP-1c activity and suppress de novo cholesterol biosynthesis possibly by inhibiting SREBP-1a activation, even under conditions of cholesterol deprivation in steroidogenic cells (Schuler et al. 1979, Rennert et al. 1990, Lehmann et al. 1997,
Repa et al. 2000, Christenson et al. 2001, Fu et al. 2001, Björkhem 2002, Horton et al. 2002). Interestingly, SREBP-1a, whose activity would be predicted to rise with prolonged steroidogenesis, may increase StAR synthesis (Christenson et al. 1998, 2001, Shea-Eaton et al. 2001). However, inhibition of endogenous SREBP-1a by $27 \mathrm{OHC}$ and LDL does not alter StAR promoter activity (Christenson et al. 2001). Thus, the apparent effect on StAR gene expression might normally be mediated by SREBP-1c or indirectly through SREBP-la-induced increases in cholesterol. This may help explain why rat R2C Leydig tumor cells which contain high levels of free cholesterol constitutively synthesize StAR and steroid (Rao et al. 2003).

In addition to regulation of StAR, oxysterols can be directly converted to steroid. This process may help explain how small amounts of steroid can still be made in StAR - / - mice and in the human placenta, which lacks StAR (Caron et al. 1997b, Pollack et al. 1997). When highly purified cytotrophoblasts are cultured in the absence of serum, steroid production appears to cease after $1 \mathrm{~h}$, indicating a loss of stimulus or an exhaustion of substrate, such as serum-derived oxysterol (Kliman et al. 1986). Given the general availability of oxysterols from peripheral, local and intracellular sources, we propose that these compounds may be responsible for much of the observed StARindependent steroidogenesis. The remainder may be a result of the unidentified factor that stimulates mitochondrial 27-hydroxylase activity in the alternative pathway of bile acid synthesis (Vlahcevic et al. 1994). These two effects of oxysterols on StAR and steroidogenesis may serve to regulate cell function locally, such as in the testis through $25 \mathrm{OHC}$, and the brain, which produces significant levels of 24 OHC (Lutjohann et al. 1996, King et al. 2002).

In summary, oxysterols increased both StAR protein and mRNA levels in a dose- and time-dependent manner in adrenocortical and Leydig cell lines with no observed effect on promoter activity. Furthermore, protein levels increased prior to detectable changes in mRNA were dependent upon new protein synthesis. Thus, we conclude that in the short term, oxysterols increase StAR protein levels independently of increased gene transcription and mRNA abundance, perhaps a result of translational regu- 
lation. We propose that oxysterols contribute to steroidogenesis through modulation of StAR activity and the direct conversion to steroid, which probably accounts for a significant proportion of StAR-independent steroid production in the body.

\section{Acknowledgements}

We thank Dr William K Wilson (Rice University, Houston, TX, USA) for critical reading of the manuscript. This work was supported by grants DK50690 (to MER), DK61548 (to S R K) and HD17481 (to D M S) from the National Institutes of Health as well as funds from the Robert A Welch Foundation (to D M S) and the Lalor Foundation (to $\mathrm{S} \mathrm{R} \mathrm{K}$ ).

\section{References}

Artemenko IP, Zhao D, Hales DB, Hales KH \& Jefcoate CR 2001 Mitochondrial processing of newly synthesized steroidogenic acute regulatory protein (StAR), but not total StAR, mediates cholesterol transfer to cytochrome P450 side chain cleavage enzyme in adrenal cells. Fournal of Biological Chemistry 276 $46583-46596$

Ascoli M, Euffa J \& Segaloff D 1987 Epidermal growth factor activates steroid biosynthesis in cultured Leydig tumor cells without affecting the levels of cAMP and potentiates the activation of steroid biosynthesis by choriogonadotropin and cAMP. Fournal of Biological Chemistry 262 9196-9203.

Bergh A, Damber J \& van Rooijen N 1993 Liposome-mediated macrophage depletion: an experimental approach to study the role of testicular macrophages. Fournal of Endocrinology 136 407-413.

Björkhem I 2002 Do oxysterols control cholesterol homeostasis? fournal of Clinical Investigation $110725-730$.

Bose HS, Sugawara T, Strauss JF, Miller WL \& The International Congenital Lipoid Adrenal Hyperplasia Consortium 1996 The pathophysiology and genetics of congenital lipoid adrenal hyperplasia New England Journal of Medicine 335 1870-1879.

Bose HS, Whittal RM, Baldwin MA \& Miller WL 1999 The active form of the steroidogenic acute regulatory protein, StAR, appears to be a molten globule. PNAS 96 7250-7255.

Bose HS, Lingappa V \& Miller W 2002 Rapid regulation of steroidogenesis by mitochondrial protein import. Nature $\mathbf{4 1 7}$ 87-91.

Caron KM, Ikeda Y, Soo SC, Stocco DM, Parker KL \& Clark BJ $1997 a$ Characterization of the promoter region of the mouse gene encoding the steroidogenic acute regulatory protein. Molecular Endocrinology 11 138-147.

Caron KM, Soo SC, Wetsel WC, Stocco DM, Clark BJ \& Parker KL $1997 b$ Targeted disruption of the mouse gene encoding steroidogenic acute regulatory protein provides insights into congenital lipoid adrenal hyperplasia. PNAS 94 11540-11545.

Chen J, Lukyanenko Y \& Hutson J 2002 25-Hydroxycholesterol is produced by testicular macrophages during the early postnatal period and influences differentiation of Leydig cells in vitro. Biology of Reproduction 66 1336-1341.
Christenson LK, McAllister JM, Martin KO, Javitt NB, Osborne TF \& Strauss JF III 1998 Oxysterol regulation of steroidogenic acute regulatory protein gene expression. Structural specificity and transcriptional and posttranscriptional actions. Fournal of Biological Chemistry 273 30729-30735.

Christenson LK, Osborne TF, McAllister JM \& Strauss JF III 2001 Conditional response of the human steroidogenic acute regulatory protein gene promoter to sterol regulatory element binding protein-la. Endocrinology 142 28-36.

Clark BJ \& Combs R 1999 Angiotensin II and cyclic adenosine 3',5'-monophosphate induce human steroidogenic acute regulatory protein transcription through a common steroidogenic factor-1 element. Endocrinology 140 4390-4398.

Clark BJ, Wells J, King SR \& Stocco DM 1994 The purification, cloning, and expression of a novel luteinizing hormone-induced mitochondrial protein in MA-10 mouse Leydig tumor cells. Characterization of the steroidogenic acute regulatory protein (StAR). Fournal of Biological Chemistry $26928314-28322$.

Clark BJ, Soo SC, Caron KM, Ikeda Y, Parker KL \& Stocco DM 1995 Hormonal and developmental regulation of the steroidogenic acute regulatory protein. Molecular Endocrinology 9 1346-1355.

Clark BJ, Combs R, Hales KH, Hales DB \& Stocco DM 1997 Inhibition of transcription affects synthesis of steroidogenic acute regulatory protein and steroidogenesis in MA-10 mouse Leydig tumor cells. Endocrinology 138 4893-4901.

Clark BJ, Ranganathan V \& Combs R 2001 Steroidogenic acute regulatory protein expression is dependent upon post-translational effects of cAMP-dependent protein kinase A. Molecular and Cellular Endocrinology 173 183-192.

Cohen PE, Hardy MP \& Pollard JW 1997 Colony-stimulating factor-1 plays a major role in the development of reproductive function in male mice. Molecular Endocrinology 11 1636-1650.

Edwards PA, Kast HR \& Anisfeld AM 2002 BAREing it all: the adoption of LXR and FXR and their roles in lipid homeostasis. Journal of Lipid Research 43 2-12.

Fu X, Menke JG, Chen Y, Zhou G, MacNaul KL, Wright SD, Sparrow CP \& Lund EG 2001 27-Hydroxycholesterol is an endogenous ligand for liver $\mathrm{X}$ receptor in cholesterol-loaded cells. Journal of Biological Chemistry 276 38378-38387.

Horton JD, Goldstein JL \& Brown MS 2002 SREBPs: activators of the complete program of cholesterol and fatty acid synthesis in the liver. Fournal of Clinical Investigation 109 1125-1131.

Javitt NB 2002 25R,26-Hydroxycholesterol revisited: synthesis, metabolism, and biologic roles. Fournal of Lipid Research $\mathbf{4 3}$ 665-670.

Jefcoate C, Simpson E \& Boyd G 1974 Spectral properties of rat adrenal-mitochondrial cytochrome P-450. European Fournal of Biochemistry 42 539-551.

King SR, Manna PR, Ishii T, Syapin PJ, Ginsberg SD, Wilson K, Walsh LP, Parker KL, Stocco DM, Smith RG et al. 2002 An essential component in steroid synthesis, the steroidogenic acute regulatory protein, is expressed in discrete regions of the brain. fournal of Neuroscience 22 10613-10620.

Kliman H, Nestler J, Sermasi E, Sanger J \& Strauss JF III 1986 Purification, characterization, and in vitro differentiation of cytotrophoblasts from human term placentae. Endocrinology 118 $1567-1582$.

Krueger R \& Orme-Johnson N 1983 Acute adrenocorticotropic hormone stimulation of adrenal corticosteroidogenesis. Discovery of a rapidly induced protein. Fournal of Biological Chemistry $\mathbf{2 5 8}$ 10159-10167.

Lala DS, Syka PM, Lazarchik SB, Mangelsdorf DJ, Parker KL \& Heyman RA 1997 Activation of the orphan nuclear receptor steroidogenic factor 1 by oxysterols. PNAS 94 4895-4900.

Lehmann JM, Kliewer SA, Moore LB, Smith-Oliver TA, Oliver BB, Su JL, Sundseth SS, Winegar DA, Blanchard DE, Spencer TA et al. 1997 Activation of the nuclear receptor LXR by oxysterols 
defines a new hormone response pathway. Fournal of Biological Chemistry 272 3137-3140.

Lin D \& Sugwara T 1995 Role of steroidogenic acute regulatory protein in adrenal and gonadal steroidogenesis. Science $\mathbf{2 6 7}$ $1828-1831$

Lukyanenko YO, Chen JJ \& Hutson JC 2001 Production of 25-hydroxycholesterol by testicular macrophages and its effects on Leydig cells. Biology of Reproduction 64 790-796.

Lutjohann D, Breuer O, Ahlborg G, Nennesmo I, Siden A, Diczfalusy U \& Björkhem I 1996 Cholesterol homeostasis in human brain: evidence for an age-dependent flux of 24S-hydroxycholesterol from the brain into the circulation. PNAS 93 9799-9804.

Meaney S, Bodin K, Diczfalusy U \& Björkhem I 2002 On the rate of translocation in vitro and kinetics in vivo of the major oxysterols in human circulation: critical importance of the position of the oxygen function. Fournal of Lipid Research 43 2130-2135.

Mellon SH \& Bair SR 1998 25-Hydroxycholesterol is not a ligand for the orphan nuclear receptor steroidogenic factor-1 (SF-1). Endocrinology 139 3026-3029.

Miller W 1997 Congenital lipoid adrenal hyperplasia: the human gene knockout for the steroidogenic acute regulatory protein. Fournal of Molecular Endocrinology 19 227-240.

Pollack SE, Furth EE, Kallen CB, Arakane F, Kiriakidou M, Kozarsky KF \& Strauss JF III 1997 Localization of the steroidogenic acute regulatory protein in human tissues. Fournal of Clinical Endocrinology and Metabolism 82 4243-4251.

Rao RM, Jo Y, Leers-Sucheta S, Bose HS, Miller WL, Azhar S \& Stocco DM 2003 Differential regulation of steroid hormone biosynthesis in R2C and MA-10 Leydig tumor cells: role of SR-B1-mediated selective cholesteryl ester transport. Biology of Reproduction 68 114-121.

Rennert H, Fischer R, Alvarez J, Trzaskos J \& Strauss JF III 1990 Generation of regulatory oxysterols: 26-hydroxylation of cholesterol by ovarian mitochondria. Endocrinology 127 738-746.

Repa JJ, Liang G, Ou J, Bashmakov Y, Lobaccaro JMA, Shimomura I, Shan B, Brown MS, Goldstein JL \& Mangelsdorf DJ 2000 Regulation of mouse sterol regulatory element-binding protein-1c gene (SREBP-1c) by oxysterol receptors, LXR $\alpha$ and LXR $\beta$. Genes and Development 14 2819-2830.

Repa JJ, Berge KE, Pomajzl C, Richardson JA, Hobbs H \& Mangelsdorf DJ 2002 Regulation of ATP-binding cassette sterol transporters ABCG5 and ABCG8 by the liver $\mathrm{X}$ receptors $\alpha$ and ß. Journal of Biological Chemistry 277 18793-18800.

Reyland ME, Williams DL \& White EK 1998 Inducible expression of protein kinase $\mathrm{C} \alpha$ suppresses steroidogenesis in Y-1 adrenocortical cells. American Fournal of Physiology 275 C780-C789.

Reyland ME, Evans RM \& White EK 2000 Lipoproteins regulate expression of the steroidogenic acute regulatory protein StAR in mouse adrenocortical cells. Fournal of Biological Chemistry 275 36637-36644.
Rommerts FFG, King SR \& Span PN 2001 Implications of progesterone metabolism in MA-10 cells for accurate measurement of the rate of steroidogenesis. Endocrinology 142 $5236-5242$.

Russell D 2000 Oxysterol biosynthetic enzymes. Biochimica et Biophysica Acta 1529 126-135.

Schimmer B 1979 Adrenocortical Y1 cells. Methods in Enzymology 58 570-574.

Schuler LA, Scavo L, Kirsch TM, Flickinger GL \& Strauss JF III 1979 Regulation of de novo biosynthesis of cholesterol and progestins, and formation of cholesteryl ester in rat corpus luteum by exogenous sterol. Fournal of Biological Chemistry 254 8662-8668.

Schwarzenbach H, Manna PR, Stocco DM, Chakrabarti G \& Mukhopadhyay AK 2003 Stimulatory effect of progesterone on the expression of steroidogenic acute regulatory protein in MA-10 Leydig cells. Biology of Reproduction 68 1054-1063.

Shea-Eaton WK, Trinidad MJ, Lopez D, Nackley A \& McLean MP 2001 Sterol regulatory element binding protein-la regulation of the steroidogenic acute regulatory protein gene. Endocrinology 142 $1525-1533$.

Stocco DM 2001 StAR protein and the regulation of steroid hormone biosynthesis. Annual Review of Physiology 63 193-213.

Stocco DM, Clark B, Reinhart A, Williams S, Dyson M, Dassi B, Walsh L, Manna P, Wang X, Zeleznik A et al. 2001 Elements involved in the regulation of the StAR gene. Molecular and Cellular Endocrinology 177 55-59.

Sugawara T, Holt J, Kiriakidou M \& Strauss JI 1996 Steroidogenic factor 1-dependent promoter activity of the human steroidogenic acute regulatory protein (StAR) gene. Biochemistry 35 9052-9059.

Vlahcevic ZR, Hylemon PB \& Chiang JYL 1994 Hepatic cholesterol metabolism. In Liver, Biology and Pathobiology, edn 3, pp 379-389. Eds IM Aria, JL Boyer, N Fausto, WB Jakoby, DA Schachter \& DA Shafritz. New York: Raven Press Inc.

Walsh LP \& Stocco DM 2000 Effects of lindane on steroidogenesis and steroidogenic acute regulatory protein expression. Biology of Reproduction 63 1024-1033.

Wang X, Liu Z, Eimerl S, Timberg R, Weiss A, Orly J \& Stocco D 1998 Effect of truncated forms of the steroidogenic acute regulatory protein on intramitochondrial cholesterol transfer. Endocrinology 139 3903-3912.

Wigler M, Silverstein S, Lee L, Pellicer A, Cheng Y \& Axel R 1977 Transfer of purified herpes virus thymidine kinase gene to cultured mouse cells. Cell 11 223-232.

Yee J \& Hutson J 1985 Effects of testicular macrophage-conditioned medium on Leydig cells in culture. Endocrinology 116 2682-2684.

Received in final form 18 November 2003 Accepted 30 November 2003 